\title{
Patients' satisfaction with reproductive health services at Gogo Chatinkha Maternity Unit, Queen Elizabeth Central Hospital, Blantyre, Malawi
}

\section{Josephine Changole ${ }^{1}$, Chiwoza Bandawe ${ }^{2}$, Bonus Makanani ${ }^{1}$ Kondwani Nkanaunena, Frank Taulo ${ }^{1}$, Eddie Malunga ${ }^{1}$, George Kafulafula ${ }^{1}$}

1 Department of Obstetrics \& Gynaecology, College of Medicine, University of Malawi

2 Department of Mental Health, College of Medicine, University of Malawi \& Dept of Psychology, University of Cape Town

3 College of Medicine-Johns Hopkins Research Project, Blantyre Malawi

\section{Abstract}

Patient satisfaction is an individual's state of being content with the care provided in the health system. It is important for reproductive health care providers to get feedback from women regarding satisfaction with reproductive health services. There is a dearth of knowledge about patient satisfaction in Malawi.

\section{Aim}

The specific objective of the study was to determine the extent to which women are satisfied with the care they receive when they come to deliver at the Queen Elizabeth Central Hospital maternity unit.

\section{Methods}

A cross sectional study of postpartum women using interviewer administered semi-structured questionnaires was conducted between November 2008 and May 2009. The questionnaires captured mainly quantitative data.

\section{Results}

1562 women were interviewed. Most women were housewives (79\%) who were referred from Health Centres within the city. Ninety five percent delivered a live baby. The majority of women (97.3\%) were satisfied with the care they received from admission through labour and delivery and the immediate postpartum period. Most women cited doctors' and nurses' reviews $(65 \%)$ as what they liked most about the care they received during their stay in the unit.

Most women expected to receive efficient and definitive care. The women's knowledge on patient's rights was extremely low $(16 \%)$ and equally very few women were offered an opportunity to give an opinion regarding their care by the doctors and nurses in the maternity unit.

\section{Conclusion}

Most women who deliver at the hospital are satisfied with the care offered. This satisfaction is mainly due to the frequent reviews of patients by nurses and doctors in the unit. There is a great need to educate both the population of women served and the health workers that serve them on patient's rights.

\section{Introduction}

Satisfaction is an individual's state of being contented or pleased with an event.

Lari and colleagues defined patient satisfaction as the extent of an individual's experience compared with his or her expectations or what patients' and the population as a whole desire to receive from health care services ${ }^{1}$. Health care providers, especially in the private sector are striving to keep the users of their services satisfied and numerous studies have been conducted into patient satisfaction ${ }^{2}$. Satisfied patients are likely to come back for the services they need and to recommend the services to others. Patients are deemed the best people to know what is best for them and their communities ${ }^{3}$. This study therefore, explored patients' satisfaction at Queen Elizabeth Central Hospital, in Malawi. The study outcome was that the findings would provide feedback to health care providers, local administrators, managers and policy makers at the national level in order to promote patients' satisfaction.

\section{Background}

Emulating the marketing world, where companies are always striving to improve the quality of their products to achieve customer satisfaction by getting feedback from the customer, health research has been conducted to look at what satisfies a patient. Lari and colleagues noted that patients' satisfaction is linked to the extent to which general health care needs are met. Subsequently satisfied patients are more likely to comply with treatment, take an active role in their own health care and continue using health care services. They concluded that satisfaction surveys could help identify potential areas for service improvement and help optimize health expenditure through patient guided planning and evaluation ${ }^{1}$.

Similarly, in a three year analysis survey of patients' satisfaction carried out in Germany, Sweden, Switzerland, the United Kingdom and United states, it was found that patient satisfaction surveys could assist in local quality improvement efforts and facilitate the identification of poor quality care for further investigation and interventions among others ${ }^{4}$. It was clear from the survey that in all the five countries, patients were commonly concerned (or dissatisfied) with information and education, coordination of care, respect for patients' preferences, emotional support, physical comfort, involvement of family and friends, and continuity and transition of care. Fitzpatrick also noted similar concerns from patients ${ }^{5}$.

Detailed questions about specific aspects of patients' experiences are more likely to be useful for monitoring performance of various hospital departments and wards. This then influences delivery of health care services and its improvement ${ }^{6}$. Other researchers have found that patients are naturally more satisfied when they are empowered with knowledge $\mathrm{e}^{7}$. Another important finding by these authors was that patients want to be informed, have choices and be protected; hence providers should strive to provide an environment which both empowers and protects patients. ${ }^{8}$ In a study that was done in Uganda to measure patients' satisfaction, it was found that the major concern of patients was on improving customer care, increasing staff levels, improving on buildings, lighting and cleanliness ${ }^{9}$. Health care consumers expect professional competence, accurate diagnosis, state of the art treatment and no preventable complications that might result in a longer hospital stay or prolonged recovery, disability or death ${ }^{10}$. Despite such high expectations from patients, as customers of health services, most health facilities find it a challenge to meet these expectations fully. In Germany, patients reported lack of involvement in the planning of health care process and that they felt they were not being taken seriously. Patients also felt 
that their diagnoses had not been disclosed empathetically and that they were insufficiently informed about their disease ${ }^{11}$.

A study on Zambian women's experiences of urban maternity care indicated that despite the women reporting $89 \%$ good care, $21 \%$ reported remembering someone who had treated them badly by shouting or scolding them during labour and one fifth reported having been left alone in the labour room ${ }^{12}$.

In a study done at a health centre in Malawi looking at quality of care and its effects on utilization of maternity services at a primary level, a high degree of satisfaction was noted among patients with providers' attitude $(97 \%)$, technical competence $(86 \%)$, and working hours $(91 \%)$. However, they expressed dissatisfaction with lack of privacy ${ }^{13}$.

Recent evidence from the Cochrane systematic reviews however has shown that patient-centered approach will improve patients' satisfaction. Patient-centered approach involves shared control of consultations, decision about interventions or management of the problems with the patient. The approach focuses the consultation on the patient as a whole person who has individual preferences situated within social contexts ${ }^{14}$.

Despite having many studies done elsewhere, there is paucity of data concerning patient satisfaction with the health services they receive in hospitals in Malawi.

\section{Rationale}

Chatinkha Maternity Unit at Queen Elizabeth Central Hospital (QECH) offers a wide range of out-patient and in-patient reproductive health services. Comments from the QECH 'Suggestion Box' placed at Chatinkha Maternity Unit reception (September, 2006) showed that out of the eleven people who put in their suggestions, only one person indicated that she was satisfied with the care she got while in the unit. A formal study to evaluate how satisfied women are with these services had never been conducted. There was, therefore, a clear need to formally evaluate patients' satisfaction at this unit.

This study therefore the looked at what mothers think about the services they get and what improvements are needed. The results from this study provide important feedback to the QECH management, health care providers, other health policy makers and the community that will lead to improvement in the quality of care and patient satisfaction with reproductive health services at QECH.

\section{Objectives}

The aim of the study was to establish the extent to which mothers are satisfied with the reproductive health services they receive at Chatinkha Maternity Unit of QECH and therefore recommend to the health service providers and policy makers ways of improving patient care and satisfaction.

\section{Methods}

\section{Design}

This was a cross section study of postpartum mothers that used semi-structured questionnaires to collect data between November, 2008 and May, 2009.

Questions focused on demographic data, women's feelings either good or bad about the health care they received from the reception on admission to the unit, and in-patient care, the general hygiene in the unit, and the patient-provider relationship they experienced.

\section{Study Population and Site}

The study was conducted at Chatinkha Maternity Unit, of QECH. Chatinkha Maternity Unit is one of the busiest maternity units in Malawi. The unit has a total of 250 beds for both gynaecology and obstetric patients. The unit conducts approximately 14000 deliveries per year, of which 15 percent are caesarean section deliveries. The unit also offers Family Planning services to approximately 2000 new clients per year and antenatal care to approximately 1,300 new mothers per year, with an approximate total of 5000 visits per year for the antenatal care clinic. Mothers who deliver in the unit and those who deliver elsewhere and are referred for one reason or the other to the unit are taken care of in two postnatal wards within the unit. Additionally, the unit also sees approximately 2000 new gynaecology out patients with an annual average of 7500 gynaecology consultations ${ }^{15}$.

The unit is used for teaching and training in medicine, nursing and midwifery for students from the University of Malawi College of Medicine and Kamuzu College of Nursing, Malawi College of Health Sciences, Trinity and St Joseph Colleges of Nursing. The study site was chosen because care at the unit had recently attracted negative media attention with regard to patient care. ${ }^{16,17,18} 19$

The study included mothers being discharged from the two postnatal wards. It was estimated that from the total of 14000 deliveries per annum, by the end of the proposed three months period of data collection for the study, a total of 3,500 postnatal mothers would be interviewed. We intended to interview all eligible mothers being discharged from the postnatal wards.

\section{Inclusion and Exclusion Criteria}

All the consenting women were interviewed in the in-depth interviews. Mothers who laboured elsewhere but upon referral delivered at the unit were also included. Mothers who delivered outside the unit, delivered by elective caesarean section and those who did not give consent were excluded.

\section{Data Collection and Analysis}

Exit in-depth interviews using semi-structured questionnaires were conducted with mothers from postnatal wards on the day of discharge from the ward. This was conducted in Chichewa by trained non medical interviewers.

The data were entered into the computer and analysed by SPSS.v.15.

Descriptive analysis was done.

\section{Results}

\section{Descriptive Statistics}

A total of 1562 clients, admitted at Chatinkha maternity ward between 3rd October 2008 and 30th January 2009, were interviewed. Table 1 summarizes socio-demographic characteristics of the interviewees. 
Table 1:Socio-demographic characteristics of interviewees

\begin{tabular}{|c|c|c|}
\hline Characteristic & Sumn & \\
\hline Mean Age in years (sd) & 24 & $(5.8)$ \\
\hline $\begin{array}{l}\text { Education level } \mathrm{n}(\%) \\
\text { None } \\
\text { Primary } \\
\text { Secondary } \\
\text { Tertiary }\end{array}$ & $\begin{array}{l}88 \\
847 \\
595 \\
32\end{array}$ & $\begin{array}{r}(5.6) \\
(54.2) \\
(38.1) \\
(2.0)\end{array}$ \\
\hline $\begin{array}{l}\text { Occupation } \mathrm{n}(\%) \\
\text { Employed } \\
\text { Housewife } \\
\text { None } \\
\text { Self-employed }\end{array}$ & $\begin{array}{l}66 \\
1190 \\
60 \\
246 \\
\end{array}$ & $\begin{array}{r}(4.2) \\
(76.2) \\
(3.8) \\
(15.7) \\
\end{array}$ \\
\hline $\begin{array}{l}\text { Religion } \mathrm{n}(\%) \\
\text { Christian } \\
\text { Muslim } \\
\text { Other }\end{array}$ & $\begin{array}{l}1395 \\
161 \\
6 \\
\end{array}$ & $\begin{array}{r}(89.3) \\
(10.3) \\
(0.4) \\
\end{array}$ \\
\hline $\begin{array}{l}\text { Mode of delivery } \mathrm{n}(\%) \\
\text { Breech } \\
\text { Caesarian section } \\
\text { SVD } \\
\text { Vacuum extraction }\end{array}$ & $\begin{array}{l}9 \\
366 \\
1146 \\
41 \\
\end{array}$ & $\begin{array}{r}(0.6) \\
(23.4) \\
(73.4) \\
(2.6)\end{array}$ \\
\hline $\begin{array}{l}\text { Fetal outcome } n(\%) \\
\text { Fullterm still birth } \\
\text { Live birth } \\
\text { Macerated still birth Neonatal } \\
\quad \text { death }\end{array}$ & $\begin{array}{l}16 \\
1492 \\
7 \\
47\end{array}$ & $\begin{array}{r}(1.0) \\
(95.5) \\
(0.4) \\
(3.0)\end{array}$ \\
\hline
\end{tabular}

\section{Care on Admission}

1253 women $(80.2 \%)$ were referred to Queen Elizabeth Central Hospital Chatinkha ward from other health facilities. The other 309 women (19.8\%) came to Queen Elizabeth Central Hospital without being referred. Nearly all of the women who were referred expressed no objection to the referral. Of those who were not referred, the majority responded that they chose QECH because of specialist care $(54.7 \%)$ or it was the nearest health facility (31.1\%). 1253 women $(80.2 \%)$ were referred to Queen Elizabeth Central Hospital Chatinkha ward from other health facilities. The other 309 women $(19.8 \%$ ) came to Queen Elizabeth Central Hospital without being referred. Nearly all of the women who were referred expressed no objection to the referral. Of those who were not referred, the majority responded that they chose QECH because of specialist care $(54.7 \%)$ or it was the nearest health facility (31.1\%). 172 women $(11.2 \%)$ responded that they had preconceived ideas about Chatinkha ward before admission. Of the 172 women who had preconceived ideas about Chatinkha ward, 134 (77\%) expected to be mistreated. None of them thought they would be tested for HIV when admitted and only $2(1.1 \%)$ thought students would train on them.

When asked how they were received upon admission, more than $60 \%$ of the women mentioned good reception upon admission.
Fig 1:How participants were received upon admission

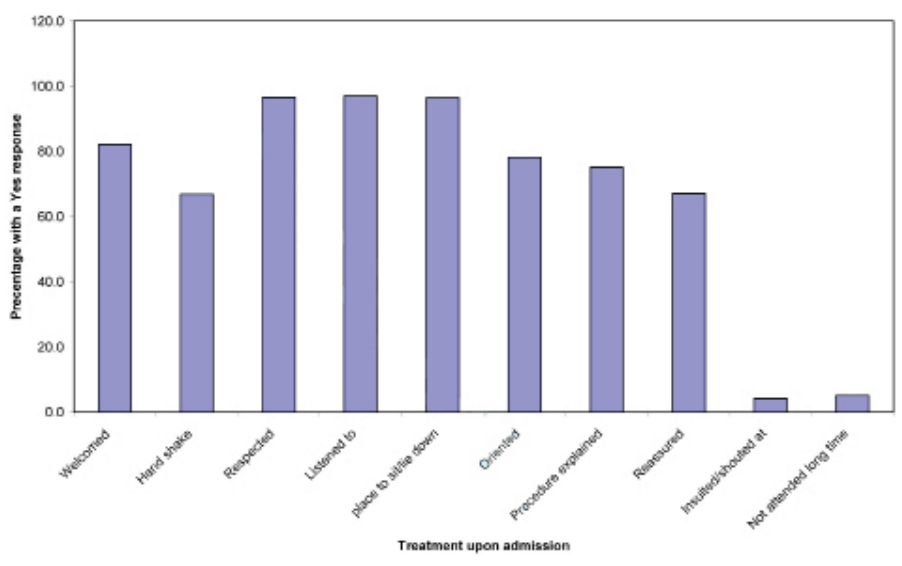

Only 451 respondents $(28.9 \%)$ indicated that the health care provider introduced himself/herself to them. Of those who had a health care provider introduce himself/herself to them, $282(65.2 \%)$ responded that the health care provider was a nurse while 111 (24.6\%) said it was a doctor.

When asked how long they waited before being attended to by a health care provider, 1373 women (88.1\%) responded that they received prompt attention with a waiting time of less than an hour after arrival.

\section{Care during Hospital Stay}

The mean number of days in hospital was 4 with a standard deviation of 4 .

Participants were asked how many times they were reviewed by different cadres of health service providers and results are shown in Fig 2 below.

Fig 2:Frequency of review of participants by cadres of health service providers

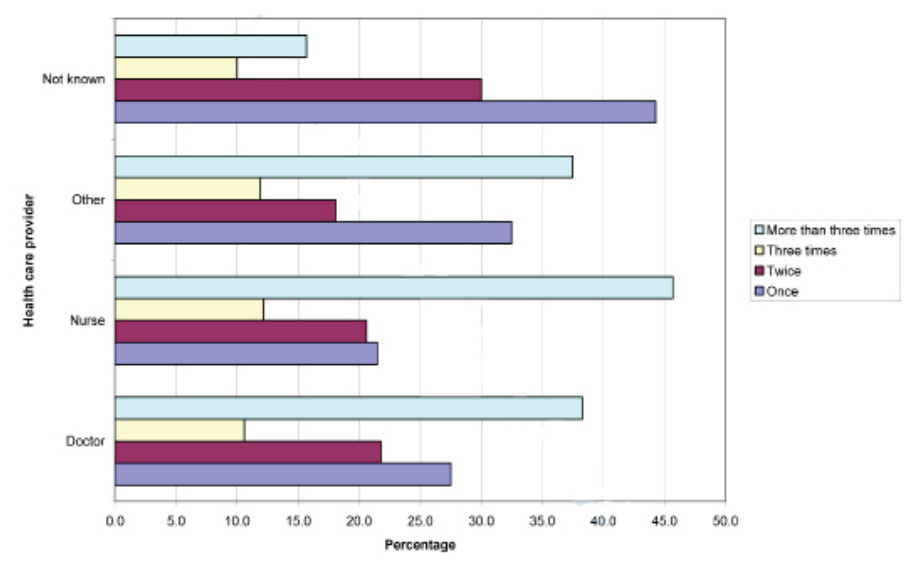

Of 1557 respondents, 1195 (76.5\%) were reviewed the way they had expected. Of the $1401(89.7 \%)$ who had underwent a diagnostic test, $1268(81.2 \%)$ responded that the doctor explained the purpose of the test to them and $1215(77.8 \%)$ had the doctor explain their condition and how they would be assisted.

Only 273 women (17.5\%) would have liked to know anything about their condition. Of these 273 , only $23(1.5 \%)$ asked the doctor/nurse for the information they wanted to know. 


\section{Knowledge of Patient Rights}

About half of the respondents, 795 (51.0\%), had ever heard of patients rights. $456(57.4 \%)$ knew that it is the right of the patient to have considerate and respectful care. This was the most well known patient right among the respondents. Other mentioned patient rights were medical information $(26.2 \%)$ and making decisions about plan of care $(23.9 \%)$. The remaining patient rights were articulated by few participants. Only $414(26.6 \%)$ responded that they were given an opportunity to choose or give their opinion on their care. And 843 women (74.3\%) would have liked to have a say on their care.

\section{Care during Labour and Delivery}

Knowledge of women on what happens during labour before it started was very high. More than $80 \%$ of the women had knowledge of the process of labour and delivery.

Women were asked to comment on the behavior of the health care provider towards them during labor. $65 \%$ of the women reported finding health care providers helpful, $37.1 \%$ responded that health service providers were friendly and $32.2 \%$ found health care providers respectful.

Almost half of the women (48\%) were accompanied by their mother during labour. Mothers were more preferred for company during labor than other relatives including husbands. $53.2 \%$ of the women preferred to be accompanied by their mothers compared to $10 \%$ preferring their husbands for company during labour.

\section{Patient Assessment of Maternity Unit Facilities}

Patient assessment of the hygiene of maternity facilities and health service providers were favourably rated. More than $90 \%$ of respondents rated hygiene in the admission room and health service providers as good or very good. A lower percentage of the respondents, less than $20 \%$, rated hygiene in the toilets and showers of the antenatal and postnatal rooms as being either poor or very poor.

\section{Patient Overall Assessment of Care}

$99.1 \%$ of respondents found their relationship/interaction with the health care provider either good or very good. And $97.3 \%$ of the women interviewed were either satisfied or very satisfied with the care that they received.

When asked what they liked most about Chatinkha Maternity Unit, $65 \%$ of the participants responded that they liked the reviews done by doctors and nurses.

Less than $3 \%$ of the participants disliked Chatinkha Maternity Unit because of either delayed attendance or infrequent doctors/nurses reviews or unnecessary prolonged stay. The highest percentage of the participants disliked Chatinkha

Maternity Unit for reasons other than the ones specified in the questionnaire.

\section{Discussion}

The study has shown that what makes up patient satisfaction in Malawi is consistent with findings elsewhere. On the whole, participants were satisfied with the care given at QECH and in particular prompt attention and doctors' and nurses' reviews. This demonstrates that patients seek dignity and respect while they are undergoing care. Labour and childbirth are vulnerable times and the need for attention and care is very important. There is also a desire on the part of patients to participate in the process of care as demonstrated by the patients' need for information about what is happening. The patients expected professional care and indicated that this was forthcoming. However, there was a reticence about asking doctors and nurses about the information they wanted to know. This could be due to cultural factors where it could be seen as inappropriate to question medical personnel. It is also of concern to note that almost half of the mothers who participated in the study had never heard of any patients' rights anywhere. Those who claimed to have had any knowledge knew of only one patient's right. This finding may indicate how the health care system has neglected such an important legal issue. It needs to be noted here, that at the time of the study, no single poster on patients' rights was available on the walls of the unit and no lessons were given to patients concerning their rights. This might indicate that issues of patients' rights are not a priority on the agenda of the health care providers at this unit and it needs to be considered for the benefit of the patients. But, while lack of knowledge on patients' rights appeared to reduce patients' level of satisfaction in other studies, it has had no effect in this study. This could be a controversial issue because one might argue that the very lack of knowledge of their rights by the mothers in itself might have raised the level of satisfaction in this study; considering that mothers had no standards upon which to base their expectations or experiences, forcing them to accept whatever was offered to them with gratitude.

Emerging from the study therefore are indicators of an intervention that would require education about patients' rights.

\section{Conclusion}

Most women who deliver at our hospital are satisfied with the care offered. This satisfaction is mainly due to the frequent reviews of patients by nurses and doctors in our unit. There is a great need to educate both the population of women served by our hospital and the health workers that serve them on patient's rights.

\section{References}

1. Lari, A. M, Tambulin, M and Gray, D. Patients' needs, satisfaction, and health related quality of life: Towards a comprehensive model. Health and Quality of Life outcomes 2004, 2:32 Editorial.

2. Wiegers, T. The quality of maternity care services as experienced by women in the Netherlands. Pregnancy \& Childbirth 2009, 9: 18-25

3. Sagid, M.S \& Baig, M.K. Quality of health care: an absolute necessity for public satisfaction. International Journal of Health Care Quality Assurance 2007, Vol.20 No.6. pp.545-548

4. Coulter, A \& Cleary, P. Patients' experiences with hospital care in five countries: patients' assessments of hospital care are essential to improving its quality. Health Affairs 2001, Vol.20, No.3

5. Fitzpatrick, R. Capturing what matters to patients when they evaluate their hospital care. Quality and safety in health care, 2002; 11:306(commentary)

6. Jenknson, C.Coulter,A.,Bruster,S.,Richards,N.,\& Chandola,T. Patients' experiences and satisfaction health care: results of questionnaire study of specific aspects of care. Quality and safety in health care, 2002; 11:335-339.

7. Press Ganey Associate Inc. Empowered patients are more satisfied with their care. The Satisfaction Monitor, Mar/Apr 1999.pp1-2.

8. Hawkers, N. Patient satisfaction levels remain in critical condition. Times News Papers Online, April 24, 2008 
9. Lochoro, P. Measuring patient satisfaction in UCMB health institutions. Health Policy and Development. Dec. 2004, Vol.2, No.3.pp.243-246.

10. Messner, L.R., and Lewis, J.S. Increasing patient satisfaction: a guide for nurses. 1996 New York: Springer Publishing Company, Inc.

11.Kleeberg,U.R., Tews,J.T., Ruprecht,T.,Hoing,M.,Kuhlmann, A.,\& Runge, C. Patient satisfaction and quality of life in cancer outpatients:resultsof the PASQOC* study. Support Care Cancer 2005, 13: $303-310$

12. MacKeith, N., Chinganya, O.J.M, Ahmed, Y. and Murray, S.F. Zambian Women's experiences of urban maternity care: results from a community survey in Lusaka. African Journal of Reproductive Health, Vol.7, No.1, Apr. 2003, pp.92-102.

13. Lule, G.S., Tugumisirize, J., \& Ndekha, M. Quality if care and its effects on utilization of maternity services at health centre level. East African Medical Journal 2000, Vol.77, No.5, pp.250-255

14. Lewin, S. A, Skea, Z. C, Entwistle, V., Zwarenstein, M., Dick, J. Interventions for providers to promote a patient centred approach in clinical consultations. The Cochrane Database of Systematic Reviews 2005, Issue www.update-software.com/abstracts/htm downloaded $15 / 05 / 2008$

15. Kanyighe,C.,Channon,A.,Tadesse,E., Madise, N., Changole,J.,Baku wa,E.,Malunga,E., \& Stones,R.W. Determinats of Post-partum Maternal Mortality at Queen Elizabeth Central Hospital, Blantyre, Malawi: A case- control study 2001-2002. African Journal of Reproductive Health. Dec.2008 vol.12, No.3:35-48

16. Nyirenda, D. Doctors threaten to boycott work. The Daily Times February1, 2007.

17. Simutowe, Y. Nurses suspended for negligence. The Daily Times,
September, 5, 2007

18. The Daily Times, May 31, 2007 (Commentary): Nurses ought to be humane.

19. Kandiero,C. \& Simutowe,Y. Nurses stay away from work. The Daily Times, May 9, 2008;

\section{Acknowledgement}

- Director and administration, Centre for Reproductive Health at College of Medicine for funding

- Head, Department of Obstetrics \& Gynaecology

- Johns Hopkins-College of Medicine Research Project, Blantyre

- Mothers who participated in the interviews.

- Interviewers.

\section{Medical Council of Malawi}

Continuous Professional Development

From May 2008 all qualified medical and Dental practitioners are required to obtain $5 \mathrm{O} \mathrm{CPD}$ points in order to renew their licence

\section{PUBLISH AN ARTICLE WITH MALAWI MEDICAL JOURNAL AND OBTAIN 10 POINTS}

Under CPD code C: publications in reference journal as principal or co-author contribute 10 points.

For subscriptions and advertisement please contact the MMJ Office in the Microbiology Building at College of Medicine, Mahatma Gandhi Campus, Blantyre. 